\title{
The causes and countermeasures of the barrier between normal colleges and primary and secondary schools
}

\author{
Ren Fangying \\ Xianyang Normal University, Xianyang, Shaanxi, 712000
}

Keywords: Higher Normal University, normal education, primary and secondary schools, basic education; Contact barrier

\begin{abstract}
At present, there are some disjointed phenomena between the teaching research and the basic education practice in normal universities in our country, and the barrier between normal colleges and primary and secondary schools is deepening. Teachers colleges and universities must strive to establish and continuously consolidate the links with primary and secondary schools. We should pay attention to multi-channel establishment and primary and secondary cooperation relations, based on the practice of basic education to improve teaching and research, and effectively maintain the unimpeded communication channels in practice. Since entering the new century, China's higher normal education has entered a new era of transformation. The general trend is to achieve the level of upgrading, the establishment of an open, integrated teacher education system. Teacher Education in Normal Colleges is still the first priority. ${ }^{[1]}$ As machine tools for training teachers in colleges and universities and teachers' pre-employment and post-vocational education bases, teachers colleges teaching, scientific research and educational practice should be closely related to the practice of primary and secondary schools, which is an important precondition for the healthy development of higher normal education in our country.
\end{abstract}

\section{The Actual State and Questions of the Higher Teacher Education}

\subsection{The Actual State of Teachers colleges and universities}

But in recent years, the higher teacher education has been deepening the reform, but there are some worrying tendencies. The decreasing connection between normal universities and primary schools, and the deepening barrier are one of the obstacles to the continuing development of normal education. Since the end of last century, China's higher normal education and basic education gradually formed their own independent development system. In addition to enrollment and employment, and the education practice of graduates, between normal colleges and primary and secondary schools there are few other business links. Therefore, it often appears that the curriculum reform in primary and middle schools is in full swing, but the teachers in colleges is still; the scientific research in universities is voluminous, but the primary and secondary school teachers know little about them, which has a negative impact on the development of our educational undertakings. The most direct result is the separation of teaching and scientific research in normal universities.

Taking modern literature teaching in normal University as an example, there is a serious 
dislocation phenomenon in the teaching of Chinese in the middle school. The textbook text, teaching content and methods of modern literature in normal universities have little consideration or even disregard for the actual situation of the middle school Chinese teaching. ${ }^{[2]}$ This phenomenon is prevalent in the teaching of many teachers of higher education. There are quite a lot of courses in normal universities becoming formalized and abstract, even the course of subject pedagogy is more deductive from theory to theory, lack of practical verification, especially lack support of vivid and lively foundation education examples. Teachers in normal colleges and universities usually bury themselves in their professional research, even the teachers of educational practice instruction seldom grassroot to the primary and secondary schools to investigate. And some scholars ' research achievements in primary and secondary education are mostly confined to the academic circle, and seldom can be accepted by teachers in primary and middle schools. Some teachers in new curriculum of teacher training for primary and secondary school teachers, in the class after the students talk to the teacher for reform of new ideas, but the teachers in the normal university ask students what is currently used in primary and secondary school textbooks. Some teachers of normal colleges and universities even have not contacted the subject of the curriculum in the middle school textbooks. ${ }^{[3]}$ Many of the academic exchanges in normal colleges and universities coming to do the report currently in the professional research are those who have made a considerable contribution to the university, in order to highlight the cutting edge of its scientific research and cutting-edge. Few experienced primary and secondary school teachers can enter the University auditorium. Because of the shortage of funds and the lack of cooperation between primary and secondary schools, the practice time is often compressed in the education and teaching practice of teachers college graduates. All these are the concrete manifestation of the contact barrier between normal universities and primary and secondary schools, which seriously affects the quality of college graduates.

\subsection{The Questions of Teachers colleges and universities}

The reasons for the above phenomenon are quite complicated, including two aspects: teachers colleges themselves and primary and secondary schools. From the normal University itself, first of all, the policy orientation of the management of teachers ' colleges leads to the barrier between them and primary schools. In the process of transformation to the comprehensive university, some teachers colleges and universities are seeking big and high, they have set up higher standards in the course setting, teaching material arrangement, and the examination and approval of scientific research projects, and constantly use sophisticated standards to measure the process of scale, specialization and regularization. In addition, some teachers colleges and universities do not pay attention to the new teachers pre-job trainnings. They attract high-educated people to come to teach in high salaries. And the teachers are arranged a heavier teaching task. In fact, the actual original practice and the teacher grassroots exercise are abolished for many years. And the practical experience of middle school teachers, even if they get a higher degree, want to go to the podium of Teachers College, the first degree of the restrictions becomes their insurmountable threshold. The policy-oriented highdemand, contempt of education and teaching practice, artificially make obstacles between teachers colleges and primary and secondary schools.

Secondly, the scientific research in normal universities has a tendency of high formalization and high abstraction. After more than 100 years of development of normal education in our country, the

teaching content, teaching methods and school-running mode have already formed certain norm. The academic research is becoming more and more profound, and the branch of subject tends to be more subtle. The continuous development of theoretical research often falls into a misunderstanding from theory to theory. Teachers ' scientific research in normal colleges and universities is also more focused on theoretical innovation, focusing on the discussion of cutting-edge academic issues, while less 
attention is paid to the relatively superficial, more operational primary and secondary education practice, and many teachers ' academic research in normal universities is divorced from the practice of basic education and separated from the teaching work they are engaged in. This led to their teaching for a long time mechanically repetitive, less innovative, less vivid content. The pursuit of scientific research-oriented abstraction makes teachers in normal universities lack the internal motive force of communication with primary and secondary schools, making it difficult for them to really face the grass-roots level and devote the necessary attention to the reform of basic education.

From primary and secondary schools, some primary and secondary schools are not actively cooperating with teachers colleges and universities, especially those with higher teaching level and strong scientific research ability. They are not keen to strengthen ties with teachers colleges and universities, and worry about working with normal universities to dilute the normal work and influence the quality of teaching. Therefore, there is a wary connection with teachers colleges and universities. Most primary and secondary schools are concerned about the quality of their teaching due to the impact of further studies and competitions. The exchange and cooperation with normal colleges and universities does not necessarily bring about the improvement of teaching quality in primary and secondary schools, and the cooperation between teachers and universities in practice, which provides the platform of teaching practice, often brings some "troubles" to the management of primary and secondary schools, and in some extent, it increases the difficulty of management. Therefore, the cooperation of some primary and secondary schools and normal universities is negative. In addition, primary and secondary school teachers in the new curriculum reform practice, the use of modern teaching means, teaching methods and other aspects, put a lot of energy, but also accumulated a certain amount of experience. Due to the theoretical literacy is not high, the task is heavy, and so on, they can not come up with the system of scientific research, and lack of psychological and material preparation for equal communication with normal universities.

\section{Teachers colleges and universities should strengthen the connection with primary and secondary schools}

China's higher normal education has entered the stage of consolidation and adjustment, and strengthening the connection with primary and secondary schools is the only way to improve higher education quality. To strengthen the connection with primary and secondary schools, normal colleges and universities should do the following in practical operation.

\subsection{Multi-channel development channels, effective establishment of cooperation with primary and secondary schools}

It is a long-standing practice to establish the connection between normal universities and primary schools. One of the aims of setting up high school and elementary in many normal colleges is to strengthen the connection. At present, the role of elementary as a link between teachers college and primary and secondary schools has not been fully exerted. Many high-school high-school elementary in normal colleges or universities have been unification by the management of the university lost its due vitality. The quality of teaching is not higher, either the higher quality and independence is stronger, already and ordinary primary and secondary schools no difference. Because of the enlargement of the school-running scale, only a few affiliated schools have been used as the base of teaching practice, which is far from satisfying the need. Therefore, in addition to the effective strengthening of the association with affiliated schools, it is also necessary to make great efforts to establish a more stable educational and teaching practice base in conjunction with other schools.

At present, many teachers colleges and universities to establish practice base is the practice of regular delivery of interns to the relevant primary and secondary schools, from the university to pay 
for a certain amount of internship guidance. In fact, the trainees to the primary and secondary schools and teachers colleges and universities should be mutually beneficial win, for the primary and secondary schools, not just pay. If the establishment of the internship base can really promote the development of relevant primary and secondary education and teaching work, primary and secondary schools and colleges and universities to cooperate with the association will be quite active.

In addition to consolidating traditional channels of communication, teachers colleges and universities should expand new channels of communication. The construction of teachers ' development school is a useful attempt to strengthen the connection between normal universities and primary schools, and moreover sending teachers to the countryside, two-way hooks, and training of order-type talents are all the contact methods that teachers colleges and schools can choose according to their actual choice.

\subsection{Change the concept, based on basic education practice and improve teaching and research}

How to strengthen scientific research work in normal colleges and universities, what is the unique academic of higher normal universities, has been the focus of academia. For teachers colleges and universities, education research is the focus of their scientific research work, and basic education is the main practice of educational research must be combined. The scientific research activities of normal colleges and universities must pay attention to serve the educational practice, serve the basic education, pay attention to the problems in the practice of basic education, and strengthen the consciousness of investigation and problem. Overcoming the highly formalized and highly abstract research tendencies that are completely divorced from our educational practice. ${ }^{[4]}$

An important segment of cultivating process of talents in teachers college is students' employment.

${ }^{[5]}$ Teachers colleges and universities should establish the concept of serving the basic education, and use practical policies to encourage the teacher and other scientific researchers to carry out research in practice. Normal Colleges should change the concept of cooperation, while sending teachers and students to the primary and secondary schools, at the same time teachers who from grassroots should be invited on university classroom, teaching reform of teaching and research experience, so can achieve truly two-way interactive communication. Teachers colleges and universities should also change the concept of employing. In addition to requiring teachers with insufficient experience in teaching to exercise at the grassroots level, practice deeply. And pay attention to the achievement of basic education and take into account of the achievements of primary and secondary education, so can create more opportunities for primary and secondary school teachers to ascend the university podium.

\subsection{We should overcome all kinds of obstacles and keep the channels of communication flowing}

It is necessary to keep the communication channels between teachers colleges and primary and secondary schools with the common efforts of the teachers and the social parties. For teachers and students in both normal and primary schools, they begin to engage in cooperative exchanges with a sense of novelty and curiosity, but it is difficult to ensure effective contact and cooperation with a momentary sense of freshness in a long-term. In practice, the cooperation between primary and secondary schools and normal universities is often beginning to be more pleasant, but later more contradictions are difficult to achieve accomplishment. In the practice of education, interns in normal colleges and universities must experience a process from unfamiliar to skillful, which will have some unfavorable effects on the education and teaching work in primary and middle schools. Therefore, before appointing interns, teachers colleges and universities will create opportunities to encourage students to carry out educational and teaching practices in schools, under the guidance of the teachers, to do a solid work in the school exercises, for the internship platform to do a good job of preparation. 
In the internship school, guide the interns patiently and carefully consult, repeated changes in the training and avoid hasty before getting on the platform, so can decrease some unnecessary losses. At the same time, government departments should support the cooperation of normal universities and primary and secondary schools, introduce relevant incentive policies, mobilize the enthusiasm of cooperation between primary and secondary schools, and dredge the channels of communication. Only by winning the affirmation and support of the relevant education administration departments can the normal universities and primary and secondary schools cooperate with each other to carry out the activities smoothly.

Talent Training Model emphasizes specific training objectives and training paths. ${ }^{[6]}$ The "two skins" of teachers ' colleges and primary and secondary schools have become one of the bottlenecks restricting the development of our educational undertakings. With the deepening of education and teaching reform in primary and secondary schools, the training of talents in normal universities faces new challenges. Teachers colleges and universities must change their ideas, eliminate the barriers to primary and secondary school links, outreach to find problems, and practice research, so the primary and secondary schools can grasp the direction of their own development timely and dynamically adjust talent training program. Only in this way can teachers ' colleges fully play the role of the new teacher training cradle, to cultivate more outstanding talents for our country's educational cause.

\section{References}

[1] Zhang Jishun. Teacher Education and the transformation of Normal University in Shaanxi [J]. Normal University Journal (Philosophy and Social Science), 2005 (5).

[2] Du Express, Du Chenmei. Dislocation: Chinese contemporary literature teaching in normal university and middle school Chinese education [J]. Education Theory and practice, 2006 (one).

[3] Yu Mingyuan, Cao Jianwen. Subject Teaching Method--The soft rib of normal education [J]. Journal of Inner Mongolia Normal University (Education Science Edition), 2006 (1).

[4] Yang Zhaoshan. a probe into some problems in contemporary education research in China [J]. theoretical front of colleges and universities, 2004 (12).

[5] Wenjun, using systems thinking innovation in Colleges and Universities "One way " the internationalized talented training paths [J]. Journal of Xianyang Normal University.

[6] Huang Keng, government regulation of the internationalized talented training in colleges and universities [J]. Journal of Yunnan University.

Author Profile: Ren Fangying, female, Shaanxi Fuping, master, lecturer, research direction: Marxism in China and ideological and political education, Xianyang Normal University, 15336114589, zip code, 712000, Address: Xianyang Normal University, Shaanxi province. 